\title{
Influence of meteorological factors on ecosystem services value: a case study of Beijing-Tianjin-Hebei region, China
}

\author{
Zhenya Zhu ${ }^{1,2, *}$, Zhengyuan Zhao ${ }^{3}$, Xiaoyuan $\mathrm{Wang}^{2}$, Hongqing $\mathrm{Li}^{2}$, Mengfei Yang ${ }^{2}$, Lihua Chen $^{1}$ \\ ${ }^{1}$ College of Soil and Water Conservation, Beijing Forestry University, 100083 Beijing, China \\ ${ }^{2}$ Changjiang Water Resources Protection Institute,430051 Wuhan, China \\ ${ }^{3}$ School of Nature Conservation, Beijing Forestry University, 10083 Beijing, China
}

\begin{abstract}
Meteorological factors are one of the natural factors, which affect ecosystem services value (ESV). Influence of meteorological factors was studied in Beijing-Tianjin-Hebei region using ordinary least square (OLS) with geographical weighted regression (GWR). The main aim of this study was to reveal the differences in the influence mechanism at the global and local levels. The main meteorological factors influencing ESV were temperature and precipitation, followed by humidity. Days with annual daily precipitation $\geq 0.1 \mathrm{~mm}$, annual minimum precipitation and annual average relative humidity were three important meteorological factors. Annual temperature range, annual minimum precipitation, days with annual daily precipitation $\geq 0.1 \mathrm{~mm}$, in particular, the last one had an obvious positive effect. The positive and negative effects of annual average relative humidity were coexisting, and the negative effect was the main. It was obvious that the spatial distribution characteristics of the local influence mechanism. The local model of GWR can better solve the spatial non-stationarity of the dependent and independent variables, thus it was better than the global model of OLS. The results also provide detailed field information on the different effects of meteorological factors at different locations.
\end{abstract}

\section{Introduction}

The impact of natural factors and human activities on global ecosystems is increasing, the resulting changes in ecosystem services and human well-being have become a focus of research attention [1]. The combination of natural factors and human activities affected ESV. That is to say, artificial factors and natural factors together led to spatial and temporal changes in the value of ecological service. The "driving forces" are a general term for the factors that cause changes in the ecosystem. There are five major types of driving forces: socioeconomic, political, technological, natural and cultural driving forces [2].The factors that directly affect the ecosystem process are called direct driving forces, which can be measured and identified at different precisions; by changing the direct driving force, indirect effects are called indirect driving forces, which determine the magnitude of action from its impact on the direct driving force [3]. Exploring the underlying mechanisms can provide an important basis for land management in an environment of greater human impact, it also helps to understand the trade-offs and synergies among multiple environmental factors [4].

Utilization of water and soil resources will change the composition of terrestrial ecosystems, which play a key role in enhancing or weakening ecosystem services $[5,6]$. Most studies about driving forces focused on the relationship between land cover/landscape changes and variation of ESV [7-10]. Based on the value assessment of land use and value coefficient, changes in land use will inevitably lead to changes in the value of ecological service, but it cannot reflect the intrinsic driving factors of the changes in the value of ecological service. Climate was very important to the spatial distribution of ecological service value [11-13], especially water-related ecosystem services [14-17]. In some studies, the selection of influencing factors was relatively casual, and the multicollinearity problem between the influencing factors was not considered. Traditional methods such as correlation analysis and multiple regression analysis were widely used. Some studies had good results which may be caused by multi-collinearity.

In fact, the regression parameters are related to the geographical location. The regression parameters of the global model are estimated by the mean of the regression parameters in the whole region, which cannot reflect the spatial variation of the regression parameters. To this end, the SVCR (Spatially Varying Coefficient Regression) [18] and the SAR (Spatial Auto Regressive) [19] were invented by foreign scholars, and the regression parameters were related to the spatial position of samples.

\footnotetext{
* Corresponding author: zhenya zhu@126.com
} 
Some scholars used a local smoothing idea and invented the GWR [20, 21], which can solve the problem of regression parameters with geographical location. This paper took 167 districts and counties in the region as the research objects, 19 meteorological factors were selected, as well as 4 ESV indicators. The multi-collinearity of independent variables was eliminated by removing variables, so the global model was established. Then the local model of meteorological factors was established by GWR. Therefore, the differences in the influence of meteorological factors at the global and local levels were revealed.

\section{Materials and methods}

\subsection{Data and processing}

The meteorological data of the research units were derived from the China Meteorological Data Network (www.data.cma.cn), including 171 meteorological observatories in the region from 1981 to 2010 (see Table 1). Because 171 meteorological stations do not cover 167 research units completely, a small number of units without data were replaced by the mean of the surrounding units.

Table 1. Main meteorological factors of the region.

\begin{tabular}{|c|c|}
\hline Factors & Indicators' meaning \\
\hline $\mathrm{X} 1$ & Sea-level barometric pressure $(\mathrm{hPa})$ \\
\hline $\mathrm{X} 2$ & Station pressure $(\mathrm{hPa})$ \\
\hline $\mathrm{X} 3$ & Annual extreme maximum station pressure $(\mathrm{hPa})$ \\
\hline $\mathrm{X} 4$ & Annual extreme minimum station pressure $(\mathrm{hPa})$ \\
\hline $\mathrm{X} 5$ & Average temperature $\left({ }^{\circ} \mathrm{C}\right)$ \\
\hline $\mathrm{X} 6$ & Annual temperature range $\left({ }^{\circ} \mathrm{C}\right)$ \\
\hline $\mathrm{X} 7$ & Average annual maximum temperature $\left({ }^{\circ} \mathrm{C}\right)$ \\
\hline $\mathrm{X} 8$ & Average annual minimum temperature $\left({ }^{\circ} \mathrm{C}\right)$ \\
\hline $\mathrm{X} 9$ & Days with daily maximum Temperature $\geq 30{ }^{\circ} \mathrm{C}$ \\
\hline $\mathrm{X} 10$ & Days with the lowest daily temperature $\leq 2{ }^{\circ} \mathrm{C}(\mathrm{d})$ \\
\hline $\mathrm{X} 11$ & Annual average relative humidity $(\%)$ \\
\hline $\mathrm{X} 12$ & Average annual precipitation from 20 to $20(\mathrm{~mm})$ \\
\hline $\mathrm{X} 13$ & Average annual precipitation from 8 to $8(\mathrm{~mm})$ \\
\hline $\mathrm{X} 14$ & Annual maximum precipitation $(\mathrm{mm})$ \\
\hline $\mathrm{X} 15$ & Annual minimum precipitation $(\mathrm{mm})$ \\
\hline $\mathrm{X} 16$ & Annual maximum daily precipitation $(\mathrm{mm})$ \\
\hline $\mathrm{X} 17$ & Days with annual daily precipitation $\geq 0.1 \mathrm{~mm}(\mathrm{~d})$ \\
\hline $\mathrm{X} 18$ & Average annual wind speed $(\mathrm{m} / \mathrm{s})$ \\
\hline $\mathrm{X} 19$ & Days with maximum daily wind speed $\geq 5.0 \mathrm{~m} / \mathrm{s}(\mathrm{d})$ \\
\hline
\end{tabular}

The ESV included Z1(total ESV), Z2 (ESV per unit area), Z3 (ESV per capita), Z4 (ESV per GDP), which came from the author's previous research results [22]. Regression analysis was carried out in spss22. It was found that meteorological factors had the greatest explanatory power for $\mathrm{Z} 2$ variation, the regression determination coefficient was $71.4 \%$. In order to facilitate the interpretation of the model, Z2 was selected as the dependent variable. The "input" method was used for regression analysis, and the established regression equation had severe multi-collinearity. In view of the specific scientific significance of meteorological factors, cull method was used to eliminate the multi-collinearity, so as to preserve the integrity of the meaning of the variables. X17, X15, X11, X6 were finally selected to enter the models, unnormalized residual was saved, drawing with * ZRESID as $\mathrm{Y}$ axis and * ZPRED as $\mathrm{X}$ axis.

\subsection{Global and local regression model}

The GWR was extended on the basis of the OLS, the regression parameters contained spatial position information of the sample points, namely:

$$
\mathrm{y}_{\mathrm{i}}=\beta_{0}\left(\mathrm{u}_{\mathrm{i}}, \mathrm{v}_{\mathrm{i}}\right)+\sum_{\mathrm{k}=1}^{\mathrm{p}} \beta_{\mathrm{k}}\left(\mathrm{u}_{\mathrm{i}}, \mathrm{v}_{\mathrm{i}}\right) x_{i k}+\varepsilon_{\mathrm{i}} \mathrm{i}=1,2, \ldots, \mathrm{n}
$$

The position information of sample $\mathrm{i}$ (such as latitude and longitude) is $\left(\mathrm{u}_{\mathrm{i}}, \mathrm{V}_{\mathrm{i}}\right)$, the $\mathrm{k}$-th regression coefficient is $\beta_{\mathrm{k}}\left(\mathrm{u}_{\mathrm{i}}, \mathrm{V}_{\mathrm{i}}\right)$, the random error was $\varepsilon_{\mathrm{i}}, \varepsilon_{\mathrm{i}} \sim \mathrm{N}\left(0, \sigma^{2}\right)$, and $\operatorname{Cov}\left(\varepsilon_{\mathrm{i}}, \varepsilon_{\mathrm{i}}\right)=0(\mathrm{i} \neq \mathrm{j})$. The above formula can be simplified to

$$
\mathrm{y}_{\mathrm{i}}=\beta_{0}+\sum_{\mathrm{k}=1}^{\mathrm{p}} \beta_{\mathrm{ik}} x_{i k}+\varepsilon_{\mathrm{i}} \quad \mathrm{i}=1,2, \ldots, \mathrm{n}
$$

If the regression coefficients of the various points were equal, GWR model become OLS model.

GWR 4.0 can be used to explore the relationship between dependent and independent variables. Since the independent variables and the dependent variable had been standardized, only the geographic variation test option was checked, creation a Gaussian GWR model.

The calibration standard selected the default AICc (AIC for small sample deviation correction). Since the model fit used an adaptive kernel, the optimal bandwidth for the golden section search was 54, that was to say, the nearest 54 units were used to estimate the local coefficients. The minimum AICc value was 266.935 .

\section{Results}

\subsection{Global influencing mechanism of meteorological factors}

\subsubsection{Output of OLS model}

The determinant coefficient $\mathrm{R}$ Square decreased from 0.707 to 0.623 , and the adjusted $\mathrm{R}$ square decreased from 0.692 to 0.616 . However, the goodness-of-fit may be caused by severe multi-collinearity. The $\mathrm{F}$ value of the regression equation was 89.678 , which was greater than $\mathrm{F}_{\mathrm{a}}(\mathrm{m}, \mathrm{n}-\mathrm{m}-1)=\mathrm{F}_{0.05}(3,163)=2.68$, that was, the regression equation was significant at the 0.05 significance level, and the established regression equation was statistically significant. At the same significance level, $|\mathrm{t}|>\mathrm{t}_{\mathrm{a}}(\mathrm{n}-\mathrm{m}-1)=$ $\mathrm{t}_{0.05}(163)=1.65$ (except for the constant), the regression 
coefficients were significant. In the collinearity statistics of the regression results, the tolerance of the independent variables was greater than 0.1 , and the VIF (Variance Inflation Factors) was less than 10, the regression equation solved the multi-collinearity of independent variables well, so the global model was proposed and the result was more reliable.

The Q-Q map of the unnormalized residual was plotted as shown in Fig.1, and the scatter plot for normalized residuals and normalized predictions was shown in Fig.2.

The observed value and the expected conventional value were distributed near a straight line of $45^{\circ}$, so the unnormalized residual approximated a normal distribution, satisfying the requirement of OLS. With the change of the regression standardized prediction value, the regression standardized residual was similarly distributed near $\mathrm{y}=0$, and the residual variance of prediction value was equal, so it was satisfied the requirement of OLS.

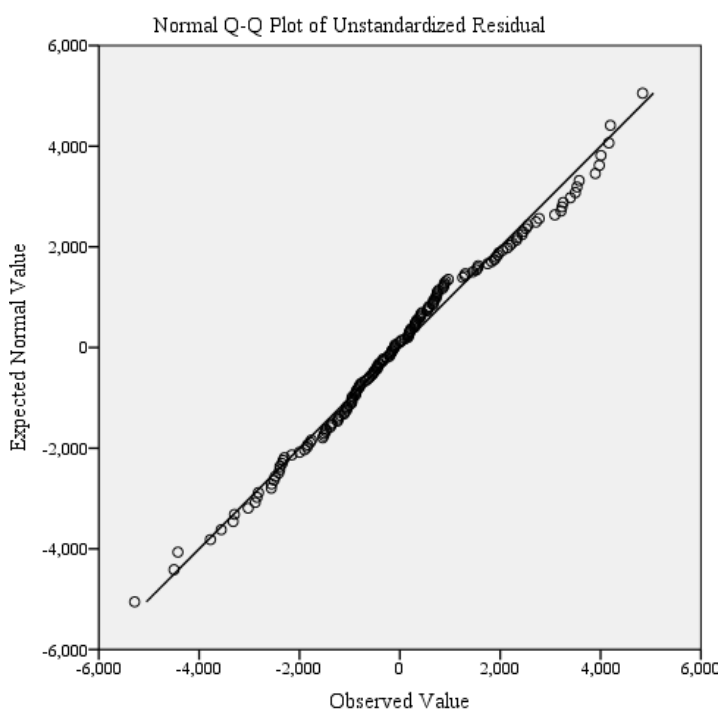

Fig.1. Normal QQ plot of unstandardized residual.

\subsubsection{Analysis of the global influencing mechanism}

Among the meteorological factors, X17, X10, X6, X15, $\mathrm{X} 1, \mathrm{X} 13, \mathrm{X} 12$, and X19 were positively correlated with $\mathrm{Z} 2$, and the other 11 factors were negatively correlated. From the Pearson correlation coefficient, temperature and precipitation were the main influencing factors, such as $\mathrm{X} 17, \mathrm{X} 15, \mathrm{X} 9, \mathrm{X} 10, \mathrm{X} 8, \mathrm{X} 5, \mathrm{X} 7$ and $\mathrm{X} 6$, followed by humidity $\mathrm{X} 11$, then air pressure, such as $\mathrm{X} 4, \mathrm{X} 3, \mathrm{X} 2$ and $\mathrm{X} 1$, wind had the least effect, such as X18, X19. X17, $\mathrm{X} 15$ and X11 entered the global model, and they were three important factors. According to the previous research, the natural background conditions of land used in the region were different, and the spatial distribution of meteorological factors also had local differences, and the overall goodness-of-fit of the global model needed to be improved. Further analysis of the local influence mechanism was needed.

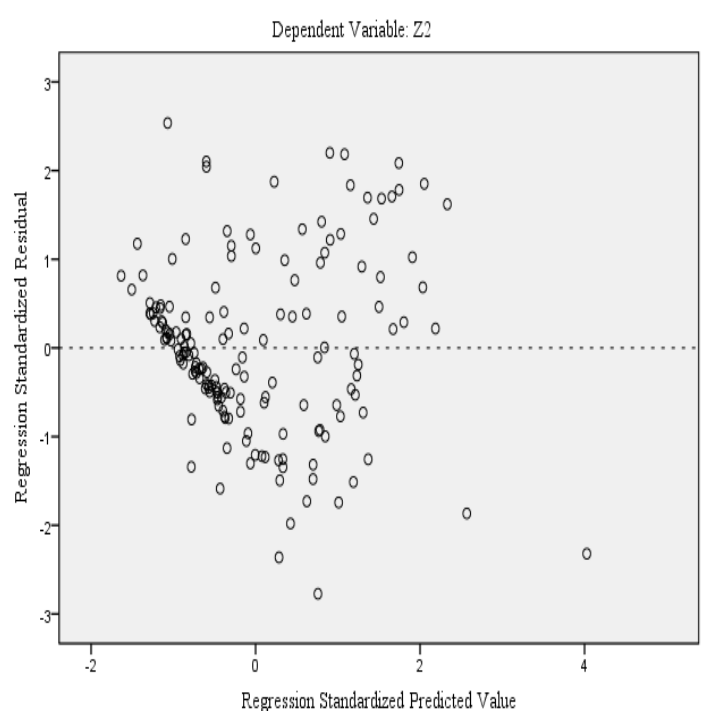

Fig.2. Scatterplot of regression standardized residual and regression standardized prediction value.

\subsection{Local influencing mechanisms of meteorological factors}

\subsubsection{Testing the fitting effect of GWR model}

Variance analysis of OLS and GWR models (see Table 2) and geographical variability test of local regression coefficients (see Table 3).

Table 2. Analysis of variance by meteorological factors.

\begin{tabular}{|c|c|c|c|c|}
\hline Source & $\boldsymbol{S S}$ & $\boldsymbol{D F}$ & $\boldsymbol{M S}$ & $\boldsymbol{F}$ \\
\hline Global Residuals & 62.515 & 162 & & \\
\hline GWR Improvement & 33.268 & 36.592 & 0.909 & \\
\hline GWR Residuals & 29.247 & 125.408 & 0.233 & 3.8983 \\
\hline
\end{tabular}

Analysis of variance can find out whether global and local model have the same statistical performance. Since each point of the geographic weighting matrix was variable, the F-test in the table was an approximate test. The results showed that the GWR model improves the effect of global regression model, that was, the GWR model solved the problem of spatial non-stationarity well, and the fitting effect of the GWR was better than the global regression model.

Table 3. Geographical variability tests of local coefficients.

\begin{tabular}{|c|c|c|c|c|}
\hline Variable & $\boldsymbol{F}$ & \multicolumn{2}{|c|}{ DOF for $\boldsymbol{F}$ test } & DIFF of Criterion \\
\hline Intercept & 3.1355 & 3.227 & 134.654 & -2.1738 \\
\hline ZX6 & 2.6283 & 4.361 & 134.654 & -0.3396 \\
\hline ZX11 & 4.5477 & 4.595 & 134.654 & -10.0979 \\
\hline ZX15 & 3.8848 & 5.74 & 134.654 & -8.2553 \\
\hline ZX17 & 2.6190 & 5.755 & 134.654 & -0.3401 \\
\hline
\end{tabular}

Note: positive value of diff-Criterion suggests no spatial variability in terms of model selection criteria. 
F test: in case of no spatial variability, the F statistics follows the F distribution of DOF for F test.

The test results included "standard deviation" of local term which compared the difference between the initial and the improved GWR model. If the improved GWR model was statistically better fitted, the value of the model comparison indicator will be less than the initial GWR, so if the "standard deviation" was positive, there was no significant spatial non-stationarity at the local. According to the test results, X6, X11, X15, and X17 were all negative values, indicating that these four variables had spatial variability, and the $F$ values did not obey the F-distribution of the F-test.

It should be noted that if the difference between AIC or AICc is greater than 2, the global model is significantly different from the local model. If the difference is greater than 3, indicating that there is significant spatial differentiation between the dependent and the independent variables, GWR is better than the OLS. The fitting results of OLS and GWR (see Table 4).

Table 4. Fitting results of OLS and GWR.

\begin{tabular}{|c|c|c|c|c|}
\hline Model & AIC & $\boldsymbol{A I C}$ & $\boldsymbol{C V}$ & $\boldsymbol{R}$ square \\
\hline OLS & 321.8326 & 322.3576 & 0.4137 & 0.6234 \\
\hline GWR & 249.6673 & 266.9346 & 0.2925 & 0.8238 \\
\hline
\end{tabular}

It can be seen that the AIC and AICc values of the GWR were 72.1652 and 55.4229 smaller than the OLS, respectively, and the difference was much larger than 3 , indicating that the GWR model was more reliable. At the same time, the CV of the GWR was also smaller than the OLS, further illustrating the reliability of the local GWR model. At the same time, the R-square and the adjusted R-square of GWR were increased by 0.2004 and 0.1532 , respectively, the GWR model can explain the greater variation of Z2. GWR better solved the problem of spatial non-stationarity of dependent and independent variables. Therefore, the GWR was better than the OLS.

\subsubsection{Statistical analysis of local coefficients}

Studying the distribution of local regression coefficients can well analyse the spatial heterogeneity of independent variables. Descriptive statistics of local regression coefficients (see Table 5).

Table 5. Descriptive statistics of local coefficients.

\begin{tabular}{|c|c|c|c|c|}
\hline Variable & Mean & STD & $\begin{array}{c}\text { Lwr } \\
\text { Quartile }\end{array}$ & $\begin{array}{c}\text { Upr } \\
\text { Quartile }\end{array}$ \\
\hline Intercept & -0.1598 & 0.3654 & -0.4563 & 0.1220 \\
\hline ZX6 & 0.2698 & 0.2428 & $\underline{0.0741}$ & $\underline{0.4806}$ \\
\hline ZX11 & -0.1202 & 0.2826 & $\underline{-0.2898}$ & $\underline{0.0490}$ \\
\hline ZX15 & 0.2745 & 0.2428 & $\underline{0.0417}$ & $\underline{0.4119}$ \\
\hline ZX17 & 0.4565 & 0.3706 & $\underline{0.1330}$ & $\underline{0.6583}$ \\
\hline
\end{tabular}

Research showed that if the lower and upper quartile of the local coefficients did not fall within \pm 1 standard deviation of the global coefficients, the spatial distribution of variables was non-stationary [23]. The upper and lower quartile range of ZX6's local coefficients were [0.074144, 0.480643], and the standard deviation range of global coefficients were [-0.030444, 0.103288]; the upper and lower quartile range of ZX11's local coefficients were $[-0.289759,0.049026]$, the standard deviation range of the global coefficients were [-0.324527, -0.203439]; the upper and lower quartile ranges of ZX15's and ZX17's local coefficients were [0.041731, $0.411948]$ and $[0.13303,0.658336]$, and the standard deviation range of global coefficients were $[0.301975$, $0.401801]$ and $[0.349686,0.48018]$, respectively. That was, the upper and lower quartiles range of ZX6's, ZX11's, ZX15's and ZX17's local coefficients did not fall within \pm 1 standard deviation of global coefficients, the local coefficients of ZX6, ZX11, ZX15 and ZX17 all had spatial non-stationarity or heterogeneity.

From the normalized local coefficients of four meteorological factors, it was known that different meteorological factors had different effects on $\mathrm{Z} 2$. There was a positive correlation between X6, X15, X17 and Z2, the three meteorological factors, especially X15 and X17, had the most positive effect on Z2. X11 and Z2 were positively and negatively correlated, negative effects were the main ones. There were 25, 33, and 19 units with negative effects, the proportion were all over $80 \%$, which was $85.03 \%, 80.24 \%$, and $88.62 \%$, respectively. There were 67 research units with positive effects, and $59.88 \%$ of the research units had negative effects in the coefficients of X11. From the whole region, X11 had a positive and negative effect, negative effects played a major role.

\subsubsection{Spatial distribution of local regression coefficients}

In ArcGIS 10.2, the natural discontinuous point grading method (Jenks) was used for visual mapping, the distribution of local coefficients was shown in Fig.3.

The spatial distribution characteristics of the local influence mechanisms were obvious. The most significant positive effect of X6 were located in Qinhuangdao and Tangshan, a small part of the border area between Baoding, Langfang and Zhangjiakou, and a small part of the southwestern in Handan and Xingtai, in most areas of the western region, there was a slight or no obvious effect. The positive effect of X6 gradually increased from northwest to northeast, east and south. The most significant negative effects of X11 were located in the Chengde and Zhangjiakou, and in the eastern part of Qinhuangdao, Tangshan, and parts of the border areas between Zhangjiakou and Hengshui, showing a slight positive effect; X11 was positive for Z2. The positive effect of X11 gradually enhanced from the north to the northeast and the south, especially the southeast. In Chengde and Zhangjiakou, X15 had the most positive effect, while in the south-central part of the region, it showed mild or no obvious effect; the positive effect of $\mathrm{X} 15$ increased gradually from the middle to the northeast 
and then to the northwest. In some areas of Shijiazhuang, Xingtai and Handan, X17 had the most positive effect, while in the south-eastern part of the region, such as Cangzhou, Hengshui and Xingtai, had a slight effect or no obvious effect; the positive effect of X17 gradually increased from the southeast to the southwest and northeast.

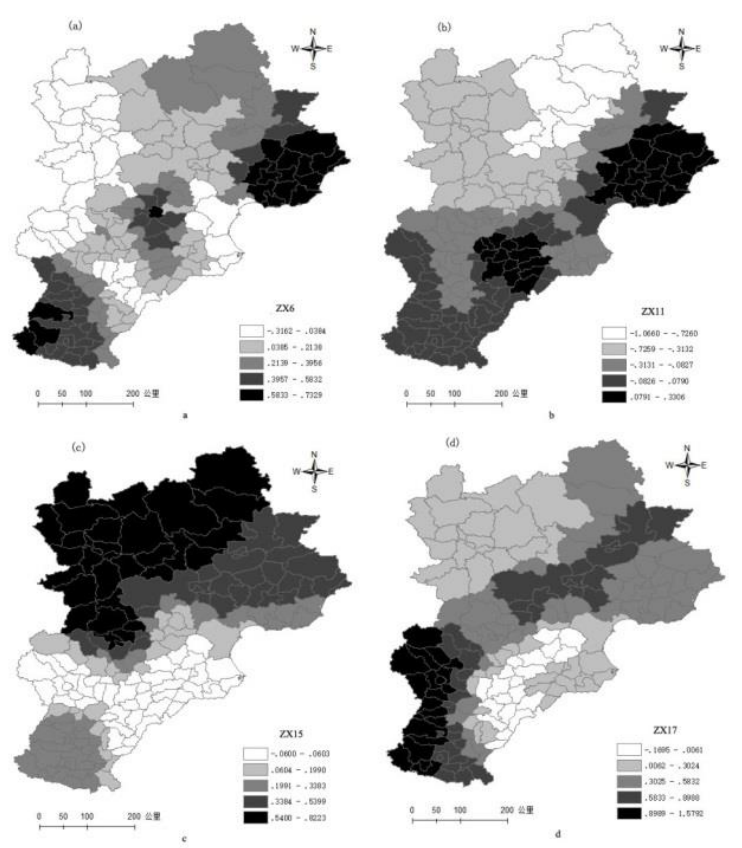

Fig.3. Local coefficients' distribution of meteorological factors.

\section{Discussion}

The dynamic interaction between the spatial distribution of biophysical cues and variable human actions, which can lead to spatial complexity of ecosystem services [24, 25].Indirect drivers, such as intensifying of economic activities and growing of population concentrations, can trigger or strengthen direct drivers [26]. In particular, with the increasing intensity and extent of human activities, humans have made substantial impacts on most of the terrestrial biosphere [27]. Meteorological factors are one of the natural factors, it is also very important to study the influence mechanism of other factors on ESV, especially the socioeconomic factors closely related to human activities.

Some studies have shown that climate change was important factor affecting ESV [28-30]. The above researches can draw preliminary qualitative or quantitative conclusions that meteorological factors have influence on ESV. They analysed the driving forces of meteorological factors from a global perspective. However, Temporal and spatial heterogeneity of meteorological factors exists objectively. Identifying the drivers of ESV and quantifying the range at which the variability comes to a steady manner will help managers to prioritize locations for different goals [31, 32]. The above researches couldn't point out the different effects of meteorological factors at different locations, which can't provide diversification guidance in policy application.

In fact, some studies used GWR model to analyse the local driving mechanism of environmental factors[33-36], but the research on ESV was very rare. In our study, OLS and GWR were integrated used to quantitatively analyse the impact of meteorological factors, which can provide targeted information with policy making. It can not only find the key meteorological factors affecting the ESV from a global perspective, but also find the local differences in the role of key meteorological factors, which is more conducive to the regulation and management of the ESV. This observation indicates the importance of using local model to analysis ecosystem drivers and highlights the influence of failing to account for the spatial autocorrelation in the OLS models [17].

\section{Conclusions}

This paper studied the global and local influencing mechanisms of meteorological factors on ESV by OLS with GWR in the region. The results showed that temperature and precipitation were the main meteorological influence factors, followed by humidity, and the drive of wind was the least. Meteorological factors were the key factors. Days with annual daily precipitation $\geq 0.1 \mathrm{~mm}$, annual minimum precipitation and annual average relative humidity were three important natural influence factors. Annual temperature range, annual minimum precipitation, days with annual daily precipitation $\geq 0.1 \mathrm{~mm}$, in particular, the last one had an obvious positive effect. The positive and negative effects of annual average relative humidity were coexisting, and the negative effect was the main effect. It was obvious that the spatial distribution characteristics of the local influence mechanism. The local model of GWR solved the problem of spatial non-stationarity of independent variables and dependent variables, thus it was better than the global model of OLS. The results also provide detailed field information on the different effects of meteorological factors at different locations.

This research was funded by National Key R\&D Program of China (NO.2016YFC0503700), and Tsinghua Rural Studies PhD Scholarship (NO.201701), playing the role in the collection, analysis, and of data.

\section{References}

1. J. Chen and Liu Y., Coupled natural and human systems: a landscape ecology perspective. Landscape Ecol. 29 (2014) 1641-1644.

2. M. Burgi, Hersperger A.M., and Schneeberger N., Driving forces of landscape change - current and new directions. Landscape Ecology. 19 (2004) 857-868.

3. MEA, Millennium ecosystem assessment synthesis. Island Press (2005).

4. Y. Yang, et al., Mapping ecosystem services bundles to detect high- and low-value ecosystem services 
areas for land use management. Journal of Cleaner Production. (2019).

5. C. Kremen, et al., Pollination and other ecosystem services produced by mobile organisms: a conceptual framework for the effects of land-use change. Ecol. Lett. 10 (2007) 299-314.

6. O. Shelef, et al., Land use Change, a Case Study from Southern Italy: General Implications for Agricultural Subsidy Policies. Land Degradation \& Development. 27 (2016) 868-870.

7. X. Huang and Ma J.X., Changes in the ecosystem service values of typical river basins in arid regions of Northwest China. Ecohydrology. 6 (2013) 10481056.

8. Y. Bai, $\mathrm{Xu}$ H., and Ling H., Eco-service value evaluation based on eco-economic functional regionalization in a typical basin of northwest arid area, China. Environmental Earth Sciences. 71 (2014) 3715-3726.

9. B. Fu, et al., Evaluation of ecosystem service value of riparian zone using land use data from 1986 to 2012. Ecol. Indicators. 69 (2016) 873-881.

10. M. Baude, Meyer B.C., and Schindewolf M., Land use change in an agricultural landscape causing degradation of soil based ecosystem services. Sci. Total Environ. 659 (2019) 1526-1536.

11. R.S. de Groot, et al., Challenges in integrating the concept of ecosystem services and values in landscape planning, management and decision making. Ecol. Complex. 7 (2010) 260-272.

12. H. Wang, et al., The influence of climate change and human activities on ecosystem service value. Ecol. Eng. 87 (2016) 224-239.

13. M. Kindu, et al., Changes of ecosystem service values in response to land use/land cover dynamics in Munessa-Shashemene landscape of the Ethiopian highlands. Sci. Total Environ. 547 (2016) 137-147.

14. R. Hoyer and Chang H.J., Assessment of freshwater ecosystem services in the Tualatin and Yamhill basins under climate change and urbanization. Applied Geography. 53 (2014) 402-416.

15. M. Marquès, et al., The impact of climate change on water provision under a low flow regime: A case study of the ecosystems services in the Francoli river basin. 263 (2013) 224-232.

16. N.R. Samal, et al., A coupled terrestrial and aquatic biogeophysical model of the Upper Merrimack River watershed, New Hampshire, to inform ecosystem services evaluation and management under climate and land-cover change. Ecol. Soc. 22 (2017).

17. M.A.A. Ahmed, et al., Spatially-explicit modeling of multi-scale drivers of aboveground forest biomass and water yield in watersheds of the Southeastern United States. J. Environ. Manage. 199 (2017) 158171.

18. S.A. Foster and Gorr W.L., An adaptive filter for estimating spatially-varying parameters: application to modeling police hours spent in response to calls for service. Management Science. 32 (1986) 878-889.

19. A.D. Cliff and Ord K., Spatial processes, models and applications. Journal of the Royal Statistical Society. 147 (1981).

20. C. Brunsdon, Fotheringham A.S., and Charlton M.E., Geographically weighted regression: a method for exploring spatial nonstationarity. Geographical Analysis. 28 (1996) 281-298.

21. Fotheringham and Stewart A., Trends in quantitative methods I: stressing the local. Progress in Human Geography. 21 (1997) 88-96.

22. Z. Zhenya, et al., Scenario simulation of ecosystem service value based on landscape transformation. Fresenius Environ. Bull. 26 (2017) 6812-6824.

23. J. Lu and Zhang L.J.F.S., Modeling and Prediction of Tree Height-Diameter Relationships Using Spatial Autoregressive Models. 57 (2011) 252-264.

24. P. Laterra, Orue M.E., and Booman G.C., Spatial complexity and ecosystem services in rural landscapes. Agriculture Ecosystems \& Environment. 154 (2012) 56-67.

25. A.K. Fremier, et al., Understanding Spatiotemporal Lags in Ecosystem Services to Improve Incentives. Bioscience. 63 (2013) 472-482.

26. Y.C. Weng, Spatiotemporal changes of landscape pattern in response to urbanization. Landscape and Urban Planning. 81 (2007) 341-353.

27. J.T. Kerr and Ostrovsky M., From space to species: ecological applications for remote sensing. Trends in Ecology \& Evolution. 18 (2003) 299-305.

28. Z.L. Tang, et al., Impacts of Land-Use and Climate Change on Ecosystem Service in Eastern Tibetan Plateau, China. Sustainability. 10 (2018).

29. M. Cheng, et al., Ecosystem Spatial Changes and Driving Forces in the Bohai Coastal Zone. Int. J. Env. Res. Public Health. 16 (2019).

30. Y. Liu, Bi J., and Lv J.S., Future Impacts of Climate Change and Land Use on Multiple Ecosystem Services in a Rapidly Urbanizing Agricultural Basin, China. Sustainability. 10 (2018).

31. B.C. Pijanowski, et al., Addressing the interplay of poverty and the ecology of landscapes: a Grand Challenge Topic for landscape ecologists? 25 (2010) 5-16.

32. S.L. Su, et al., Characterizing landscape pattern and ecosystem service value changes for urbanization impacts at an eco-regional scale. Applied Geography. 34 (2012) 295-305.

33. E.M. Costa, et al., Mapping Soil Organic Carbon and Organic Matter Fractions by Geographically Weighted Regression. Journal of Environmental Quality. 47 (2018) 718-725.

34. H.F. Teng, et al., Modelling and mapping soil erosion potential in China. Journal of Integrative Agriculture. 18 (2019) 251-264. 
35. R. Sawut, et al., Possibility of optimized indices for the assessment of heavy metal contents in soil around an open pit coal mine area. International Journal of Applied Earth Observation and Geoinformation. 73 (2018) 14-25.
36. C.X. Liu, Wu X.L., and Wang L., Analysis on land ecological security change and affect factors using RS and GWR in the Danjiangkou Reservoir area, China. Applied Geography. 105 (2019) 1-14. 